\begin{tabular}{|rl|}
\hline Title: & $\begin{array}{l}\text { A Recursive Park Transformation to Improve the Perfor- } \\
\text { mance of Synchronous Reference Frame Controllers in } \\
\text { Shunt Active Power Filters }\end{array}$ \\
Authors: & $\begin{array}{l}\text { Alberto Pigazo, Member, IEEE, Víctor M. Moreno, Mem- } \\
\text { ber, IEEE and Emilio J. Estébanez }\end{array}$ \\
Publication: & $\begin{array}{l}\text { IEEE Transactions on Power Electronics, vol. 24, no. } 9 . \\
\text { September 2009. pp. 2065-2075. }\end{array}$ \\
D.O.I.: & 10.1109/TPEL.2009.2025335 \\
\hline
\end{tabular}

(c)2009 IEEE. Personal use of this material is permitted. Permission from IEEE must be obtained for all other users, including reprinting/ republishing this material for advertising or promotional purposes, creating new collective works for resale or redistribution to servers or lists, or reuse of any copyrighted components of this work in other works. 


\title{
A Recursive Park Transformation to Improve the Performance of Synchronous Reference Frame Controllers in Shunt Active Power Filters
}

\author{
Alberto Pigazo, Member, IEEE, Víctor M. Moreno, Member, IEEE and Emilio J. Estébane
}

\begin{abstract}
Load harmonic currents and load unbalances reduce power quality (PQ) supplied by electrical networks. Shunt Active Power Filters (SAPFs) are a well-known solution which can be employed to enhance electrical PQ by injecting a compensation current at the point of common coupling (PCC) of the SAPF, the load and the electrical grid. Hence, SAPF controllers must determine the instantaneous values of the compensation reference current, including non-desirable components of the load current. A family of SAPF controllers, which evaluates the compensation reference current using synchronous rotating frames (SRFs), employs a structure based on Park Transformations: direct transform, Low-Pass Filtering (LPF) and inverse transform. The cut-off frequency and the filter order of the LPF stage must be properly designed in order to obtain an accurate reference current and a fast dynamic response of these SAPF controllers.
\end{abstract}

This paper proposes a recursive implementation of the direct Park Transformation which avoids the filtering stage and allows accurate SRF controllers to be designed. Moreover, the proposed implementation is non-dependant on PCC conditions. The proposed implementation is evaluated using a three-phase three-wire SAPF and compared with LPF based controllers by simulation and experimentally.

\section{INTRODUCTION}

Shunt active power fltering is a well-known technique employed to compensate load harmonic currents, load unbalance or load reactive power at the PCC of the SAPF, the electrical grid and the distorting load [1] [2]. A digital SAPF controller must carry on three functionalities during each sampling interval: evaluate the instantaneous values of the compensation reference current; evaluate the current consumption which is maintained by the SAPF dc-bus voltage; and ensure that the injected compensation current at the PCC matches the previously evaluated values [3]. The performance of the SAPF depends on each of these three functionalities, with the instantaneous evaluation of the compensation reference current being a key point.

The reference current can be evaluated using different approaches [2][4], the most commonly used are: the calculation of the load active and reactive power, e.g. the pq method [5]-[7] or the FBD method [8][9]; the direct evaluation of the load active current, such as SRF decomposition based methods [10]-[12]; or the evaluation of the load current

A. Pigazo, V. M. Moreno and E. J. Estébanez are with the Dept. of Electronics and Computers, University of Cantabria, Santander, 39004 Spain (phone:+34-942-201338; fax:+34-942-201303; emails: pigazoa@unican.es, morenov@unican.es, estebanezej@unican.es).

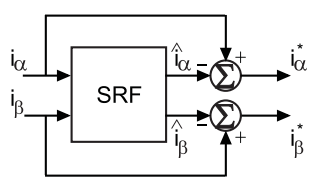

(a)

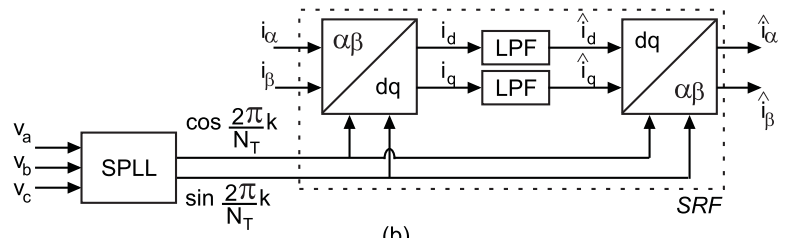

(b)

Fig. 1. a) Evaluation of the compensation reference current based on SRF methods and $b$ ) the general structure of the SRF methods

harmonic components for selective compensation, e.g. discrete Fourier transform (DFT) [13][14] or Kalman fltering [15][16]. This paper focuses on single SRF based methods for harmonic currents compensation, where the compensation reference current $i_{\alpha \beta}^{*}(k)$ can be evaluated by subtracting the target source current $\hat{i}_{\alpha \beta}(k)$ from the load current $i_{\alpha \beta}(k)$ (fg. 1.a). If selective harmonic compensation is required, more SRFs should be employed in order to establish the harmonic components of the source target current. The basic structure of SRF methods, depicted in fg. 1.b, consists of direct $D Q$ and inverse $D Q^{-1}$ Park Transformations, which allow the evaluation of a specif c harmonic component of the input signal $i_{\alpha \beta}(k)$, and a low-pass fltering stage $L P F$.

The software phase-locked-loop (SPLL) generates $\sin \omega k$ and $\cos \omega k$ functions, where $\omega=\frac{2 \pi}{N}$ and $N \in \mathcal{R}^{+}$is the number of samples which should be considered at the fundamental grid frequency, synchronized with the fundamental component of the grid voltage. These signals can be applied to $i_{\alpha \beta}(k)$ through the direct Park Transformation $(D Q)$ in order to obtain a frequency shifting effect of the harmonic components of the load current. The $D Q$ transformation output signals depend on the load current spectrum (harmonic frequency and sequence) and the performance of the SPLL. The harmonic component matching the SRF pulsation $(\omega)$ is shifted to a dc component while other frequency components of the input signal are shifted to higher frequencies, i.e. $5^{t h}$ and $7^{\text {th }}$ harmonics to $6 \omega$. Hence, the input signal components with frequency $\omega$ can be obtained after a low-pass fltering stage applied to the $D Q$ transformation outputs. Finally, the 
$D Q^{-1}$ transformation allows the target source current in $\alpha \beta$ coordinates to be obtained. As a consequence, the low-pass fltering stage must be designed carefully (cut-off frequency and flter order) in order to avoid erroneous compensation reference signals during the SAPF operation. In particular, the load current spectrum must be considered during the design process.

This paper presents a recursive implementation of the $D Q$ transform, $D Q_{r}$, which avoids the low-pass fltering stage in SRF based structures. This implementation allows an accurate evaluation of specif c harmonic components independent of PCC conditions. The mathematical analysis, simulation and experimental results obtained on a three-phase three-wire SAPF are given.

\section{SRF BASED CONTROLLERS IN THE FREQUENCY DOMAIN}

This section analyzes the frequency response of the structure shown in $\mathrm{fg}$. 1.b. and proposes a f rst approach to the recursive implementation of the Park Transformation $D Q_{r}$. As will be shown in this section, this approach is sensitive to frequency variations and a modif ed $D Q_{r}$ will be proposed.

\section{A. $D Q-L P F-D Q^{-1}$ structure}

The Park Transformation allows the load current signals to be represented using a rotating complex frame. The Park Transformation is described as:

$$
\left(\begin{array}{l}
x_{d} \\
x_{q}
\end{array}\right)_{k}=\boldsymbol{\Phi}_{k}\left(\begin{array}{l}
x_{\alpha} \\
x_{\beta}
\end{array}\right)_{k}
$$

where:

$$
\boldsymbol{\Phi}_{k}=\left(\begin{array}{cc}
\cos (\omega k) & \sin (\omega k) \\
-\sin (\omega k) & \cos (\omega k)
\end{array}\right)
$$

with $x_{\alpha}(k)$ and $x_{\beta}(k)$ being the load current components in a stationary complex frame (i.e. outputs of a Clarke Transformation), $x_{d}(k)$ and $x_{q}(k)$ the outputs of the Park Transformation and $\boldsymbol{\Phi}_{k}$ the transformation matrix obtained by means of the SPLL. The harmonic components of the load current can be f ltered-out from $x_{d}(k)$ and $x_{q}(k)$ by applying a LPF fltering stage:

$$
H_{L P F}(z)=\frac{\sum_{i=0}^{m} n_{i} z^{i}}{\sum_{i=0}^{m} d_{i} z^{i}}
$$

with $m$ being the flter order and $n_{i}$ and $d_{i}$ constant coeff cients corresponding to the numerator and denominator respectively. Butterworth flters are commonly employed in the fltering stage due to their plain gain up to the cut-off frequency.

Finally, the $\alpha \beta$ coordinates of the fundamental component of the load current at $\omega$ can be obtained by applying the inverse Park Transformation:

$$
\left(\begin{array}{c}
\hat{x}_{\alpha} \\
\hat{x}_{\beta}
\end{array}\right)_{k}=\boldsymbol{\Phi}_{k}^{-1}\left(\begin{array}{c}
\hat{x}_{d} \\
\hat{x}_{q}
\end{array}\right)_{k}
$$

where $\hat{x}_{d}(k)$ and $\hat{x}_{q}(k)$ are the fltered outputs of the $D Q$ transformation.

The $D Q-L P F-D Q^{-1}$ transformation can be analyzed in the frequency domain [17]-[20] obtaining:

$$
\begin{aligned}
& \hat{x}_{\alpha}(z)=G_{1}(z) x_{\alpha}(z)-G_{2}(z) x_{\beta}(z) \\
& \hat{x}_{\beta}(z)=G_{2}(z) x_{\alpha}(z)+G_{1}(z) x_{\beta}(z)
\end{aligned}
$$

where:

$$
\begin{aligned}
& G_{1}(z)=\frac{1}{2}\left[H_{L P F}\left(e^{j \omega} z\right)+H_{L P F}\left(e^{-j \omega} z\right)\right] \\
& G_{2}(z)=\frac{j}{2}\left[H_{L P F}\left(e^{j \omega} z\right)-H_{L P F}\left(e^{-j \omega} z\right)\right]
\end{aligned}
$$

\section{B. Proposed $D Q_{r}-D Q^{-1}$ structure}

The direct Park Transformation and the low pass fltering stage can be implemented by applying a recursive algorithm. The average values of the $D Q$ transform outputs at instants $k$ and $k-1$ can be obtained by considering $N_{r} \in \mathcal{Z}^{+}$samples at the fundamental grid frequency:

$$
\begin{aligned}
& \left(\begin{array}{l}
\hat{x}_{d} \\
\hat{x}_{q}
\end{array}\right)_{k}=\frac{1}{N_{r}} \sum_{n=k-N_{r}+1}^{k} \boldsymbol{\Phi}_{n}\left(\begin{array}{l}
x_{\alpha} \\
x_{\beta}
\end{array}\right)_{n} \\
& \left(\begin{array}{l}
\hat{x}_{d} \\
\hat{x}_{q}
\end{array}\right)_{k-1}=\frac{1}{N_{r}} \sum_{n=k-N_{r}}^{k-1} \boldsymbol{\Phi}_{n}\left(\begin{array}{c}
x_{\alpha} \\
x_{\beta}
\end{array}\right)_{n}
\end{aligned}
$$

As a consequence, the recursive Clark Transformation can be obtained:

$$
\left(\begin{array}{l}
\hat{x}_{d} \\
\hat{x}_{q}
\end{array}\right)_{k}=\left(\begin{array}{l}
\hat{x}_{d} \\
\hat{x}_{q}
\end{array}\right)_{k-1}+\frac{1}{N_{r}} \boldsymbol{\Phi}_{k}\left(\begin{array}{c}
\Delta\left(x_{\alpha}, N_{r}\right) \\
\Delta\left(x_{\beta}, N_{r}\right)
\end{array}\right)_{k}
$$

where:

$$
\begin{aligned}
& \Delta\left(x_{\alpha}, N_{r}, k\right)=x_{\alpha}(k)-x_{\alpha}\left(k-N_{r}\right) \\
& \Delta\left(x_{\beta}, N_{r}, k\right)=x_{\beta}(k)-x_{\beta}\left(k-N_{r}\right)
\end{aligned}
$$

As in the previous case, the $\alpha \beta$ coordinates of the fundamental component of the load current can be obtained by applying (4). It must be considered that, depending on the sampling frequency and the fundamental grid frequency $\omega$, the number of samples employed for the recursive implementation $N_{r}$ can be different from $N$, which is evaluated by the SPLL: The pulsation of $\sin$ and $\cos$ functions $\left(\frac{2 \pi}{N}\right)$ is changed by the SPLL to maintain the synchronization with the grid voltage. The next section discusses the effect of $N \neq N_{r}$ on this implementation.

Appendix I analyzes the recursive Park transformation in the frequency domain, obtaining:

$$
\begin{aligned}
& \hat{x}_{\alpha}(z)=G_{1, r}(z) x_{\alpha}(z)-G_{2, r}(z) x_{\beta}(z) \\
& \hat{x}_{\beta}(z)=G_{2, r}(z) x_{\alpha}(z)+G_{1, r}(z) x_{\beta}(z)
\end{aligned}
$$



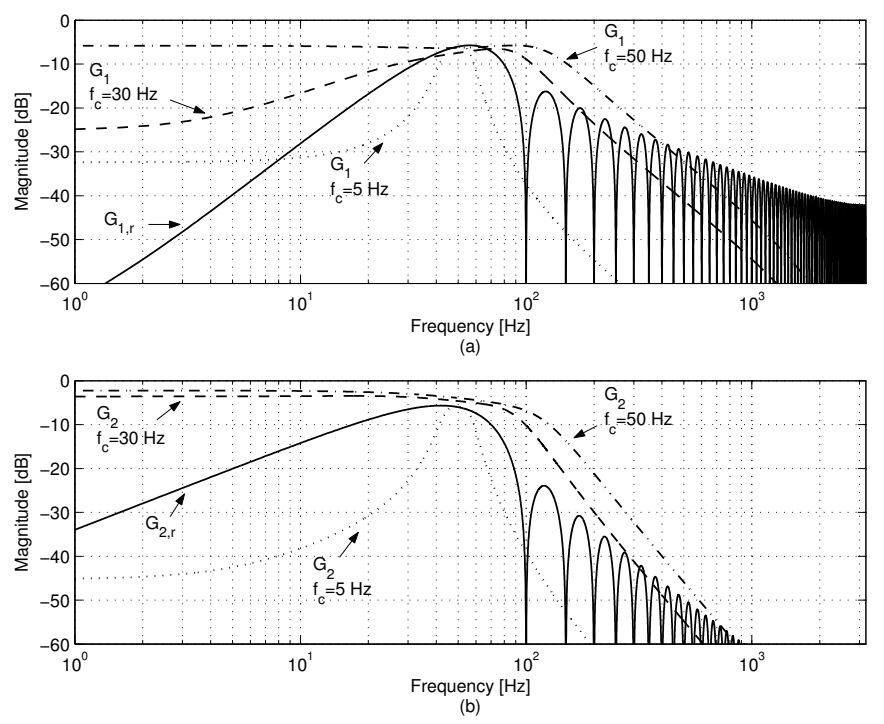

Fig. 2. Frequency responses of a) $G_{1}$ and $G_{1, r}$ and b) $G_{2}$ and $G_{2, r} . N=$ $N_{r}=128$

with:

$$
\begin{aligned}
& G_{1, r}(z)=\frac{\left(z^{N_{r}}-1\right)(z-\cos \omega)}{N_{r}\left(z^{N_{r}+1}-2 \cos \omega z^{N_{r}}+z^{N_{r}-1}\right)} \\
& G_{2, r}(z)=\frac{\left(z^{N_{r}}-1\right) \sin \omega}{N_{r}\left(z^{N_{r}+1}-2 \cos \omega z^{N_{r}}+z^{N_{r}-1}\right)}
\end{aligned}
$$

\section{Frequency domain analysis of the SRF structures}

Fig. 2 compares the frequency responses of $D Q-L P F$ $D Q^{-1}$ and $D Q_{r}-D Q^{-1}$ transformations through the analysis of the obtained transfer functions: $G_{1}(z)$ and $G_{1, r}(z)$ (f g. 2.a) and $G_{2}(z)$ and $G_{2, r}(z)$ (fg. 2.b). The analyzed $L P F$ based implementations consist of $2^{\text {nd }}$ order Butterworth flters with 5, 30 and $50 \mathrm{~Hz}$ cut-off frequencies:

$$
\begin{aligned}
H_{5 H z}(s) & =\frac{987}{s^{2}+44.43 s+987} \\
H_{30 H z}(s) & =\frac{35530.6}{s^{2}+266.6 s+35530.6} \\
H_{50 H z}(s) & =\frac{98696.0}{s^{2}+444.3 s+98696.0}
\end{aligned}
$$

As can be seen in fg. 2.a, $G_{1}(z)$ and $G_{1, r}(z)$ reach a $-6 d B$ maximum gain, which is due to the fact that both $x_{\alpha}$ and $x_{\beta}$ components contribute to the averaged outputs $\hat{x}_{\alpha}$ and $\hat{x}_{\beta}$. The LPF based method with a $5 \mathrm{~Hz}$ cut-off frequency presents the narrowest band-pass at the fundamental grid frequency but, as will be shown in the following sections, its response time under load transients is the worst. Needing a narrow band-pass in order to compensate the load current harmonics properly, slow response times can be considered as a drawback when the current harmonics of time-varying non-linear loads are compensated. The frequency response of $G_{1}$ with $f_{c}=50 \mathrm{~Hz}$ is the worst due to the fact that the attenuation for the $3^{r d}$ and $5^{\text {th }}$ harmonics is low, reaching -9.74 and $-19.25 d B$ gains respectively. Moreover, the plain gain response below $50 \mathrm{~Hz}$ does not allow low frequency load variations to be $\mathrm{f}$ ltered out. The LPF based method with $f_{c}=30 \mathrm{~Hz}$ can be an alternative for fltering out the $5^{t h}$ harmonic (its effect is reduced to $5 \%$ of its initial value) but the $3^{r d}$ harmonic remains high $(-17 d B)$ and it can not be employed in four-wire conf gurations with high load current consumption at $150 \mathrm{~Hz}$. As a consequence, depending on the load current spectrum, which can vary with the PCC voltage distortion, the LPF must be properly designed, reaching a compromise between the band-pass width of $G_{1}(z)$ and the response time under dynamical load conditions. The proposed method, as will be shown in the following sections, has a constant response time and its frequency response $\left(G_{1, r}(z)\right)$ allows undesirable harmonic components of the load current to be compensated by introducing zeros at their frequencies.

Fig. 2.b shows the frequency response obtained for $G_{2}(z)$ and $G_{2, r}(z)$. Again the LPF with $f_{c}=5 \mathrm{~Hz}$, despite being the slowest one, obtains the narrowest band-pass at the pulsation of the SRF. The dynamic response can be improved by increasing the cutoff frequency but, then, the band-pass frequencies around $\omega$ increases and, hence, the impact of harmonics different from the fundamental component increases. The effect of these load current harmonics can be minimized by means of the proposed recursive Park Transformation, which introduces multiple notches in the frequency response at their frequencies.

According to (14)-(17), the proposed recursive implementation is sensitive to frequency variations of the fundamental grid component. Rewriting (16) in a zero-pole form:

$$
G_{1, r}(z)=\frac{1}{N_{r}} \cdot \frac{z-\cos \omega}{z} \cdot \frac{\prod_{i=0}^{N_{r}-1} z-e^{j \frac{2 \pi}{N_{r}} i}}{\left(z-e^{j \omega}\right)\left(z-e^{-j \omega}\right)}
$$

In case $N_{r}=N, \omega=\frac{2 \pi}{N}=\frac{2 \pi}{N_{r}}$ and two zeros in the numerator, at $\omega$, are cancelled due to the poles in the denominator. Under $N_{r} \neq N$, such zero-pole compensation can not be done and, as a consequence, a resonance around $\omega$ would appear in the frequency response. Moreover, due to the effect of non compensated zeros at $\frac{2 \pi}{N_{r}}$, a notch should be present in the frequency response at $\frac{2 \pi}{N_{r}}$. An equivalent analysis can be carried out in case of $G_{2, r}$. This effect is analyzed in $\mathrm{fg} .3$ by plotting $G_{1, r}$ at different sampling frequencies $\left(f_{s}=6.4 \mathrm{kHz}\right.$ and $\left.f_{s}=1 \mathrm{kHz}\right)$ and grid frequencies $(49,50$ and $51 \mathrm{~Hz}$ ). From f g. 3.a and 3.c, the frequency response of the proposed method is little dependent on the sampling frequency being the gain at very low frequencies the main difference $(-67.13 \mathrm{~dB}$ at $f_{s}=6.4 \mathrm{KHz}$ and $-51.71 \mathrm{~dB}$ at $f_{s}=1 \mathrm{KHz}$ ). Hence, the proposed recursive implementation can be considered an interesting alternative in SAPF controllers operating at low switching frequencies to reduce the switching losses. Due to the effect of grid frequency variations the zero of $G_{1, r}$ can not compensate for the transfer function poles at the SRF pulsation $\omega$ and, as a consequence, gain peaks appear around the SRF frequency. This phenomenon is shown in more detail in $\mathrm{fg}$. 3.b and 3.d. As can be seen, the magnitude of the gain peaks depends on the deviation of $N_{r}$ from $N$. 

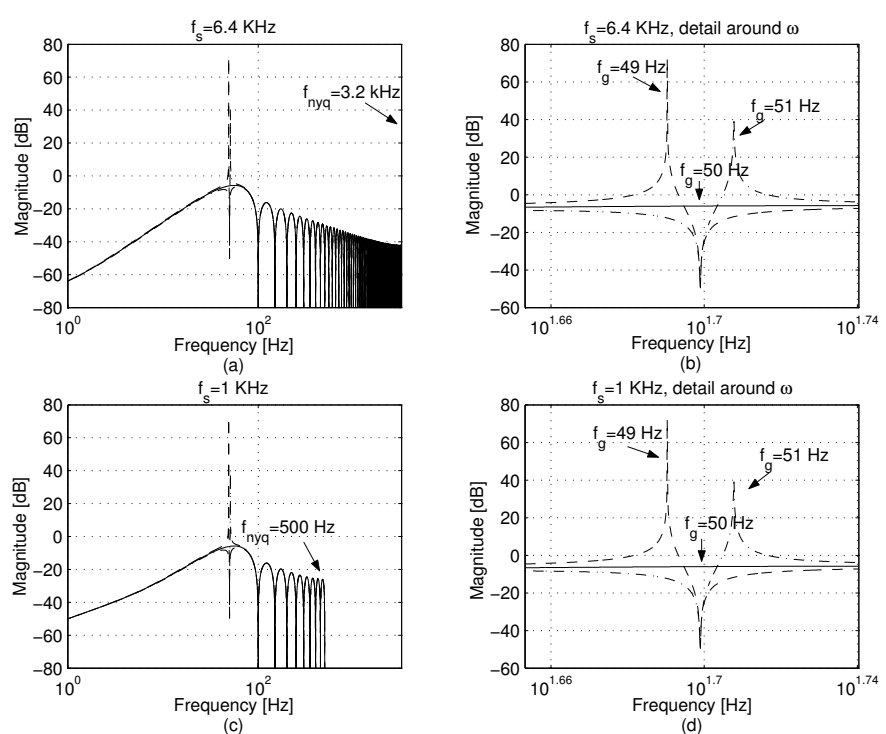

Fig. 3. Frequency response of $G_{1, r}(z)$ for different fundamental grid and sampling frequencies a) $f_{s}=6.4 \mathrm{kHZ}$, b) detail around $\omega$ at $f_{s}=6.4$ $\mathrm{KHz}, \mathrm{c}) f_{s}=1 \mathrm{KHz}$ and d) detail around $\omega$ at $f_{s}=1 \mathrm{KHz}$

\section{Modified recursive Park Transformation}

In order to avoid the effect of grid frequency variations on the proposed recursive transformation two alternatives can be employed: a) The sampling frequency of the overall controller can be changed to match $N=N_{r}$ or b) the frequency drift effect can be compensated by software. The f rst solution implies a dynamic redesign process of other elements of the SAPF controller in order to maintain their performance. This is the case of PI dc-bus voltage controllers where the proportional and integral constants should be changed to ensure the SAPF stability and compensation capability [21]. As a consequence, the second alternative has been selected.

Grid frequency variations are tracked by means of the SPLL, which changes the elements of the transformation matrix $\mathbf{\Phi}$. As a consequence, and according to (21), resonances and notches in $\mathrm{fg} .3$ are due to $\Delta$ operators in (12) and (13). In order to place properly the zeros in (21), the averaging windows corresponding to $\Delta$ operators must be dynamically resized each sampling interval. Anyway, it must be considered that only an integer number of samples $N^{\prime}$ can be applied to $\Delta$ operators while $N$ can be non-integer and, as a consequence, small frequency drifts can remain reducing the method performance. Their effect can be compensated by applying a new transformation matrix, which can be interpreted as a transformation of $\alpha \beta$ components to a second rotating frame whose pulsation corresponds to $N^{\prime}$. In this way, the poles in (21) at $\omega$ are shifted to the frequency of the previously displaced zeros and zero-pole compensation success again. Hence, the modif ed Park transformation can be def ned as:

$$
\left(\begin{array}{l}
\hat{x}_{d} \\
\hat{x}_{q}
\end{array}\right)_{k}=\left(\begin{array}{l}
\hat{x}_{d} \\
\hat{x}_{q}
\end{array}\right)_{k-1}+\frac{1}{N^{\prime}} \boldsymbol{\Theta}_{k}\left(\begin{array}{c}
\Delta\left(x_{\alpha}, N^{\prime}\right) \\
\Delta\left(x_{\beta}, N^{\prime}\right)
\end{array}\right)_{k}
$$

where

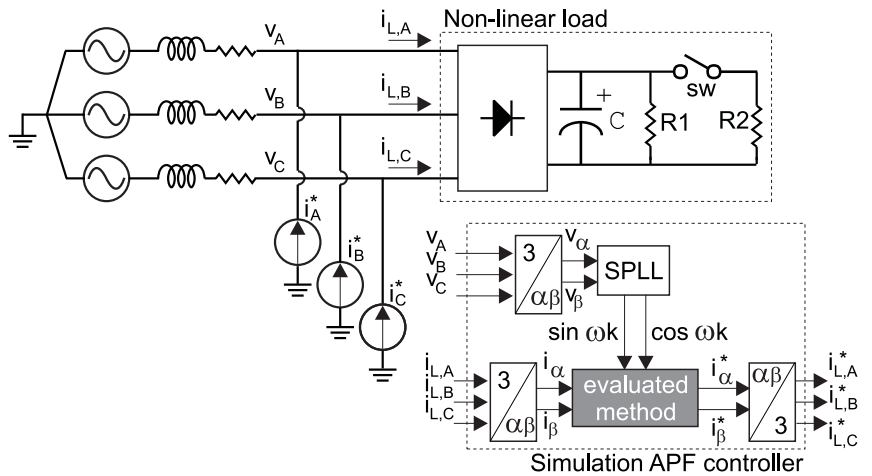

Fig. 4. Simulation model

$$
N^{\prime}=\operatorname{round}\left(\frac{1}{f_{P L L} T_{s}}\right)
$$

with $T_{s}$ being the sampling period, $f_{P L L}$ the measurement of the grid frequency obtained by means of the SPLL and

$$
\begin{array}{r}
\boldsymbol{\Theta}_{k}=\boldsymbol{\Phi}_{k}\left(\begin{array}{cc}
\cos \left(\omega_{\epsilon} k\right) & \sin \left(\omega_{\epsilon}\right. \\
-\sin \left(\omega_{\epsilon} k\right) & \cos \left(\omega_{\epsilon}\right.
\end{array}\right) \\
\omega_{\epsilon}=2 \pi\left(\frac{1}{N^{\prime} T_{s}}-f_{P L L}\right)
\end{array}
$$

In order to obtain the $\alpha \beta$ coordinates of the fundamental component of the load current the inverse Park Transformation must be modif ed:

$$
\left(\begin{array}{c}
\hat{x}_{\alpha} \\
\hat{x}_{\beta}
\end{array}\right)_{k}=\Theta_{k}^{-1}\left(\begin{array}{l}
\hat{x}_{d} \\
\hat{x}_{q}
\end{array}\right)_{k}
$$

\section{Simulation Results}

The SRF based controller depicted in fg. 1.a has been implemented in MatLab/Simulink in order to establish its performance when $D Q-L P F-D Q^{-1}, D Q_{r}-D Q^{-1}$ and modif ed $D Q_{r}-D Q^{-1}$ transformations are employed. The implementations based on LPFs apply $2^{\text {nd }}$ order Butterworth low-pass flters with cutoff frequencies $f_{c}=5 \mathrm{~Hz}$ and $f_{c}=50 \mathrm{~Hz}$. The controller sampling frequency is $f_{s}=6.4 \mathrm{KHz}$. The simulation results have been obtained considering that the controller under test is applied to an ideal SAPF, without dcbus voltage and injection current controllers, and, hence, the injection current matches the compensation reference current (fg. 4). Moreover, it is considered that only harmonic compensation is required (no reactive power compensation). The employed test load is a three-phase three-wire full-wave diode rectif er with capacitive dc side which is fed by a distorted PCC voltage according to IEEE Std. 519 [22] (3\% $5^{\text {th }}$ and $3 \% 7^{\text {th }}$ harmonics). The load dc-side characteristics can be changed during the tests in order to evaluate the dynamic response and the performance of each method. The analyzed SRF implementations have been tested under slow frequency variations of the grid voltage (different $N_{r}$ and $N$ ) and without frequency variations $\left(N_{r}\right.$ equals $N$ ) in order to establish their performance. 

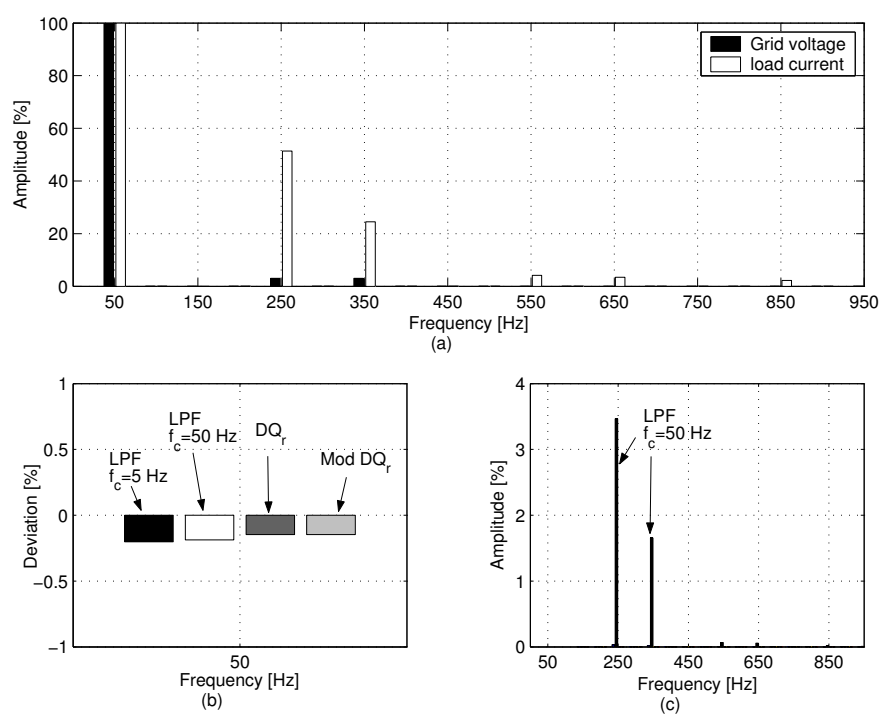

Fig. 5. Compensation results in stationary state. a) Grid voltage and load current $\left(V_{\text {base }}=20 V_{r m s}, I_{\text {base }}=3.16 \mathrm{~A}\right.$ in phase $A$ ), b) deviation from the fundamental component of the source current and c) amplitude of the harmonic components of the source current
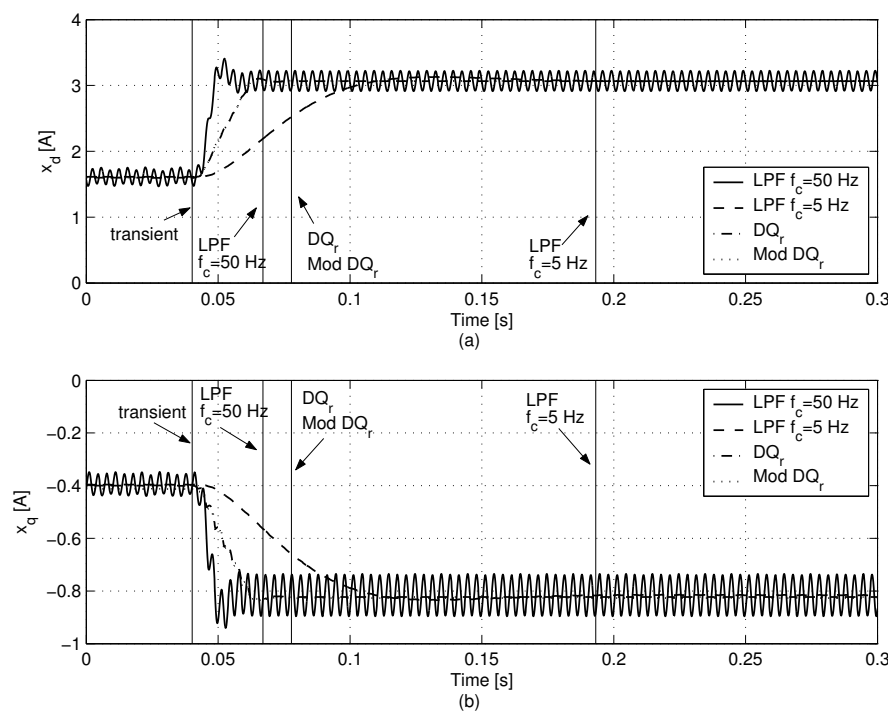

Fig. 6. Response to a load transient. a) $d$ and b) $q$ components of each SRF based controller

\section{A. $N_{r}$ equals $N$}

The grid frequency is maintained at $50 \mathrm{~Hz}\left(N=N_{r}=\right.$ 128) during the test and the performance of each method is evaluated in $a b c$ and $d q$ components. The spectra of the applied source voltage and the load current signals in phase A are shown in fg. 5.a, where the total harmonic distortion (THD) of the load current is $57.4 \%$, with high $5^{\text {th }}$ and $7^{\text {th }}$ harmonics.

Once the SAPF begins the compensation of the load current harmonics, the source current consumption at the fundamental grid component must be maintained under the simulation model depicted in $\mathrm{fg}$. 4 . The obtained results demonstrate that the deviation of the source current from the load current at the fundamental grid frequency is maintained within a maximum $0.2 \%$ (fg. 5.b) due to the employed ideal SAPF model.
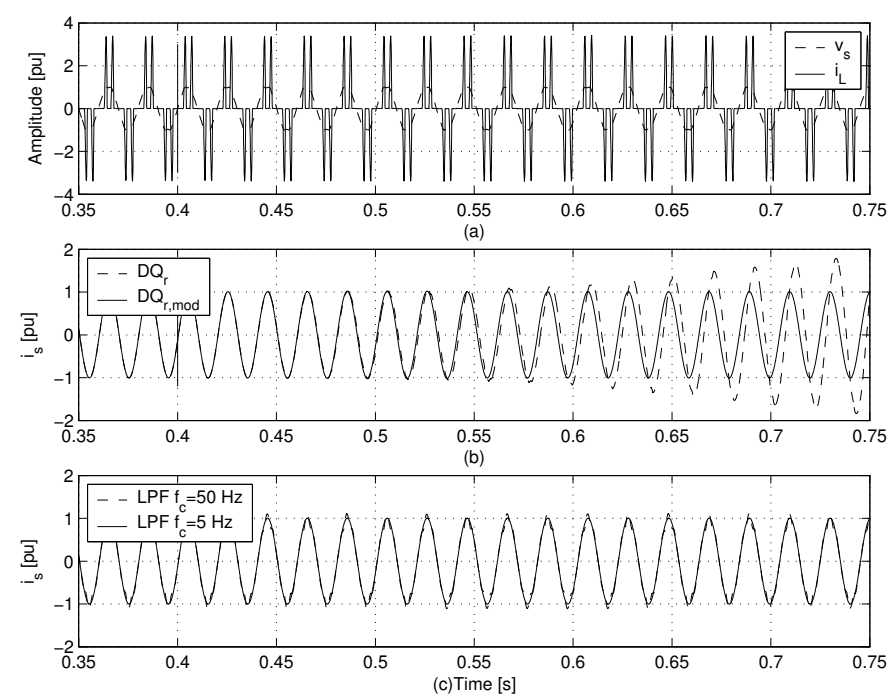

Fig. 7. SRF based SAPF controllers with a frequency variation. a) PCC voltage $v_{s}$ and load current $i_{L}$ in phase $A, \mathrm{~b}$ ) recursive and modif ed recursive DQ and c) LPF based implementations. $V_{\text {base }}=20 V_{r m s}, I_{\text {base }}=3.16 \mathrm{~A}$

The measured source current harmonics are shown in $\mathrm{fg}$. 5.c and, as can be seen, the SRF method based on the LPF with $f_{c}=50 \mathrm{~Hz}$ shows the worst performance due to the frequency response of this method. In this case, the $5^{t h}$ and $7^{t h}$ load current harmonics are only attenuated up to $3.5 \%$ and $1.7 \%$.

In order to test the performance of the SRF controllers the load current consumption changes at $0.04 \mathrm{~s}$, reaching a new steady state after $22.97 \mathrm{~ms}$. During the load transient the PCC voltage maintains its harmonic distortion levels. The inner $d q$ components of each SRF controller are shown in fg. 6.a and 6.b. The measured response times applying the recursive implementations are equivalent $\left(T_{r}=37.66 \mathrm{~ms}\right)$ while the $f_{c}=50 \mathrm{~Hz}$ LPF based method is the fastest one, with $T_{r}=26.87 \mathrm{~ms}$, and the SRF controller with a $f_{c}=5$ $\mathrm{Hz} \mathrm{LPF}$ is the slowest one $\left(T_{r}=153.2 \mathrm{~ms}\right)$. Moreover, due to the effect of the LPF both $x_{d}$ and $x_{q}$ have ripple, $9.90 \%$ and $19.13 \%$ respectively for $f_{c}=50 \mathrm{~Hz}$ and a low $0.1 \%$ and $0.2 \%$ respectively for $f_{c}=5 \mathrm{~Hz}$. As a consequence, both stationary and dynamic responses have a high dependency on the employed LPF characteristics in such SRF based controllers.

\section{B. Different $N_{r}$ and $N$}

Section II.C shows that grid frequency variations reduce the performance of the proposed recursive implementation. Hence, the SRF implementations have been analyzed under slow grid frequency variations $\left(N_{r}=128\right.$ depends on the assumed grid and sampling frequencies while $N$ is determined by the SPLL). Per unit grid voltage and load current during a frequency variation are shown in fg. 7.a. The frequency varies from $50 \mathrm{~Hz}$ at $0.4 \mathrm{~s}$ to $49 \mathrm{~Hz}$ at $0.6 \mathrm{~s}$. Due to the effect discussed in section II.C, the recursive implementation fails when compensating the load current and, as a result, the source current increases with time (f g. 7.b). The modif ed recursive implementation operates properly and maintains the source current THD below $0.3 \%$. The response of the LPF based 

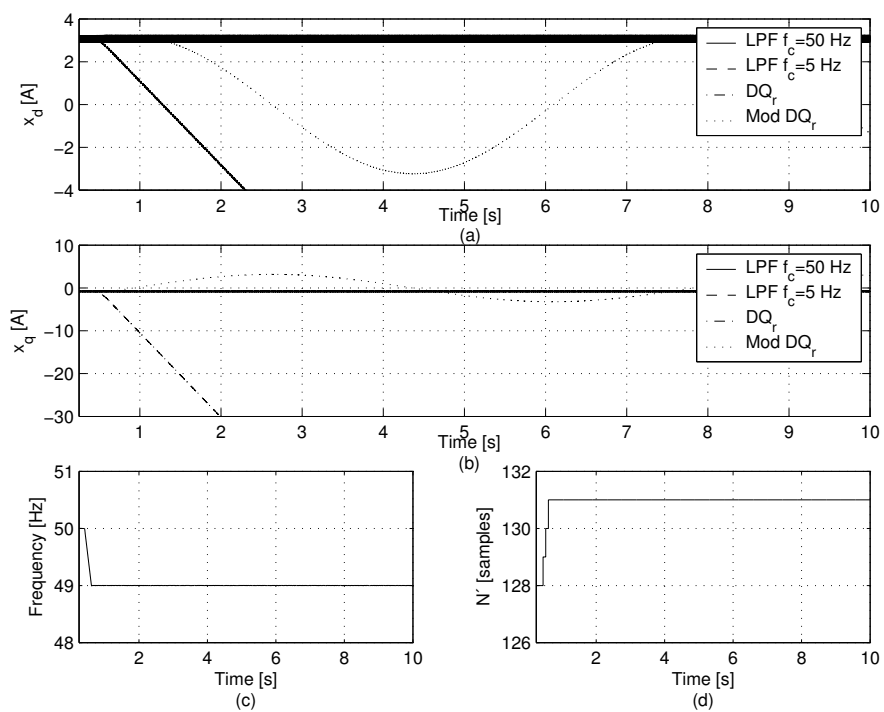

Fig. 8. SRF based SAPF controllers with a frequency variation. a) $d$ and b) $q$ components of each SRF based controller, c) the SPLL frequency measurement and d) dynamical resize of $\Delta$ operators ( $\mathrm{N}^{\prime}$ )

implementations is shown in fg. 7.c and, as in section III.A, the performance depends on the LPF stage characteristics obtaining a source THD equal to $8.6 \%$ in case of $f_{c}=50$ $\mathrm{Hz}$ and $0.3 \%$ for $f_{c}=5 \mathrm{~Hz}$. As a consequence, the proposed modif ed recursive implementation can be considered an alternative to LPF based implementations in electrical grids with frequency variations.

Fig. 8 shows the $d q$ components of each evaluated SRF method. Considering LPF based implementations, the obtained results in this case and $N_{r}=N$ are similar. In case of the recursive implementations, fg. 8.a and 8.b show that the $d q$ components of the $D Q_{r}$ method diverge and, as a consequence, the results shown in $\mathrm{fg}$. 7.b are obtained. In case of the modif ed $D Q_{r}$ method, the obtained $d q$ components are pure sinusoids whose frequency is $\frac{\omega_{\epsilon}}{2 \pi}$. This is due to the transformation to a second rotating frame. The SPLL measures the grid frequency (fg. 8.c) and the window length $\left(N^{\prime}\right)$ is dynamically resized (fg. 8.d). The oscillation in fg. 8.a and $8 . b$ is due to the remaining small frequency drift, which is compensated by means of the modif ed transformation matrix (24). As a consequence, the amplitude and frequency of these sinusoidal signals depend on the characteristics of the load current but, also, on the value of $N^{\prime}$.

\section{EXPERIMENTAL RESULTS}

The analyzed SRF based controllers have been tested using a laboratory setup whose structure is depicted in $\mathrm{fg}$. 9. A modif ed VLT - 5004 drive from Danfoss is employed as power stage of the three-phase three-wire SAPF and three inductors $(L=3 \mathrm{mH}$ and $R=1.3 \Omega)$ operate as current links. A power generator $(H P-6834-B)$ is employed to generate the harmonic distortion levels according to IEEE Std. 519 [22] $\left(3 \% 5^{\text {th }}\right.$ and $3 \% 7^{\text {th }}$ harmonics $)$ and feeds a fullwave diode rectif er with capacitive dc side $(C=2200 \mu \mathrm{F}$, $R_{1}=32 \Omega$ and $R_{2}=64 \Omega$ ). A switch $s w$ is employed to

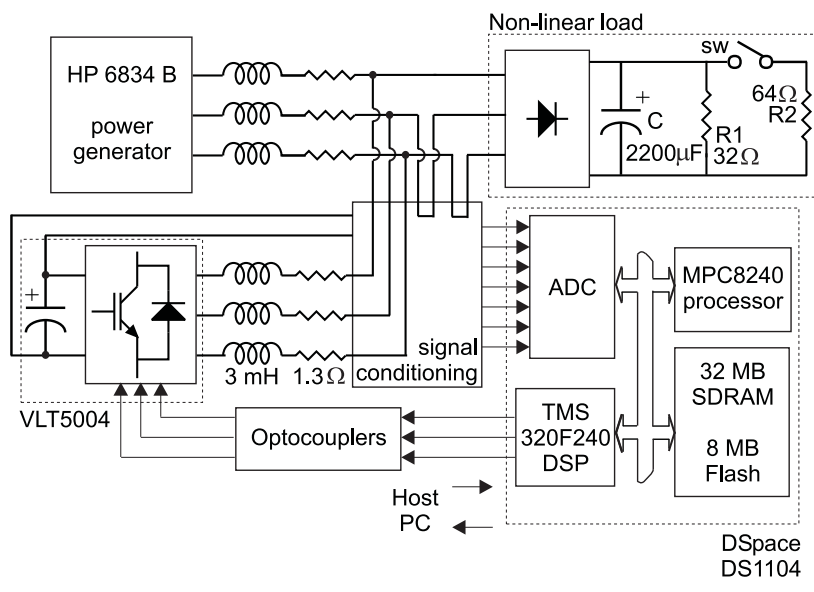

Fig. 9. Laboratory setup

generate load transients. The SAPF controller is executed in a control card $D S-1104$ from Dspace.

\section{A. SAPF controller implementations}

The SAPF controllers previously analyzed by simulation has been experimentally implemented in order to compare their performance. The general structure of the developed controller is shown in fg. 10. As can be seen, the evaluated methods share the same general structure: a SPLL, the dc-bus controller, the injection current controller and a pulse width modulator (PWM).

The measured grid voltages are normalized in order to obtain $v_{\alpha \beta}$ signals, which will be applied to the SPLL for synchronization purposes. Normalization is required in order to avoid the impact of the grid voltage amplitude on the inner PI controller gains. The SPLL input signals are transformed to a certain rotating frame whose frequency $\omega_{P L L}$ and phase are adjusted by applying a PI controller $\left(t_{\text {set }}=20 \mathrm{~ms}\right.$ and $\xi=0.707)$ to the $q$ component of the normalized input voltage signals [23][24]. As a result, the grid voltage frequency $f_{P L L}$, only required by the modif ed $D Q_{r}-D Q^{-1}$ method, and the rotation matrix $\Phi$ are obtained. In case of voltage unbalance, the SPLL structure should be modif ed in order to track the positive sequence of the grid voltage.

A PI controller allows the SAPF dc-bus voltage $V_{d c}$ to be maintained almost constant at $V_{d c}^{*}$ during the SAPF operation ensuring a proper dynamical response under load variations $\left(V_{d c}^{*}=210 \mathrm{~V}, K_{p}=0.024\right.$ and $\left.K_{i}=0.011\right)[21]$. In order to minimize the effect of transients on the integral part of the PI controller, i.e. during the SAPF start-up, an anti-windup block has been included. The current consumption which maintains the dc-bus voltage is evaluated by multiplying the PI controller output and the $\sin \cos$ signals generated by the SPLL.

The current controller must ensure that the injection current $I_{\alpha \beta}^{c}$ matches the compensation reference current. In this case, and due to the frequency spectrum of the non-linear load to be compensated, one proportional $\left(K_{p}=16.5\right)$ and three resonant blocks, with resonance frequencies at the fundamental component and the $5^{\text {th }}$ and $7^{\text {th }}$ harmonics $\left(K_{1}=10^{3}, K_{5}=2 \cdot 10^{3}\right.$ and $K_{7}=5 \cdot 10^{3}$ ), have been selected as current controllers. It 


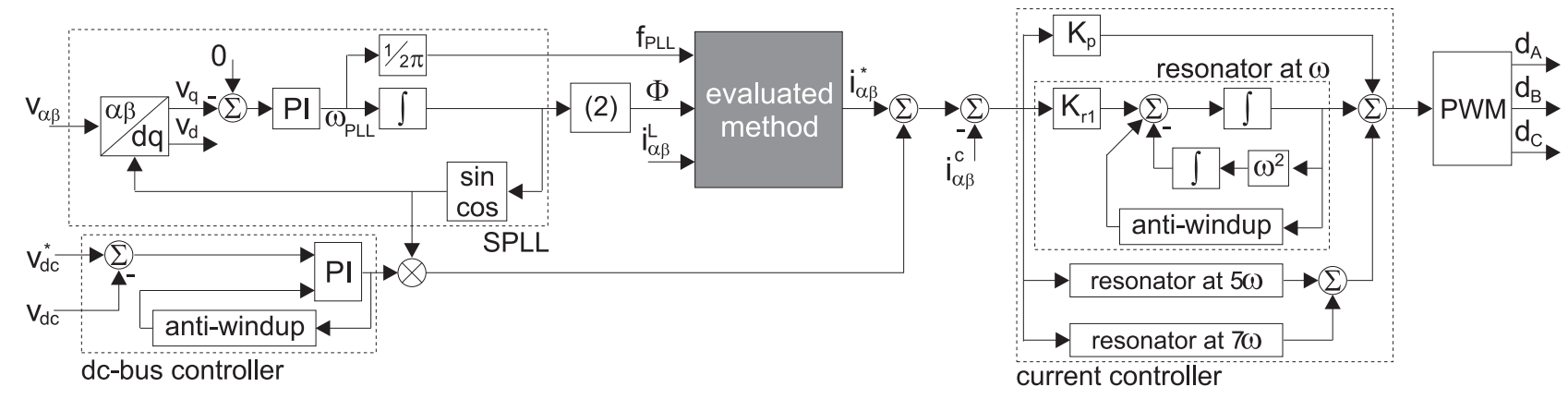

Fig. 10. Block diagram of the experimentally tested SAPF controllers

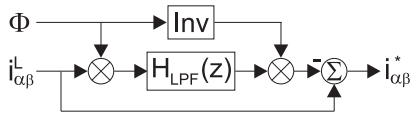

(a)

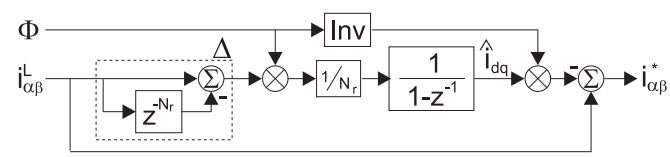

(b)

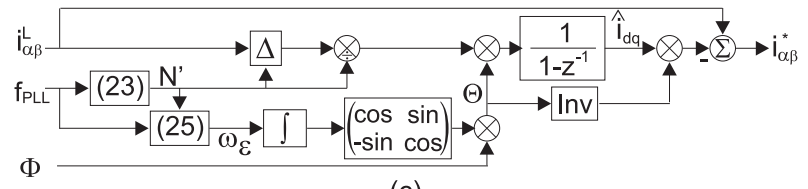

(c)

Fig. 11. Structure of the evaluated methods: a) $D Q-L P F-D Q^{-1}$, b) $D Q_{r}-D Q^{-1}$ and c) modif ed $D Q_{r}-D Q^{-1}$

must be considered that, if the frequency spectrum of the nonlinear load current contains more harmonic orders, the number of applied resonant blocks should be increased in order to introduce new resonances at at such harmonic frequencies. The inclusion of new resonant blocks, if required, could deteriorate the controller stability and, hence, the resonant block gains should be redesigned. Moreover, it must be considered that grid frequency variations can deteriorate the performance of such current controllers based on resonant blocks. Detailed information about the implementation of current controllers based on resonant blocks can be found in [25]-[29]. The structure of the implemented current controller is depicted in fg. 10 .

The current controller output signals must be applied to the modif ed VLT - 5004 drive by means of the DSP timers, which is done by evaluating the duty cycle of each inverter leg through a sinusoidal pulse width modulator [30]. The switching frequency of the SAPF is $4 \mathrm{kHz}\left(N_{r}=80\right)$.

The inner structure of the evaluated methods is shown in fg. 11. In fg. 11.a the structure of a conventional $D Q-$ $L P F-D Q^{-1}$ based method is depicted. The tested LPFs, according to (3), have been implemented as discrete $2^{\text {nd }}$-order Butterworth flters with $5 \mathrm{~Hz}$ and $50 \mathrm{~Hz}$ cut-off frequencies. The structure of the implemented recursive Park transformation is shown in fg. 11.b. Both $\Delta$ operators are implemented

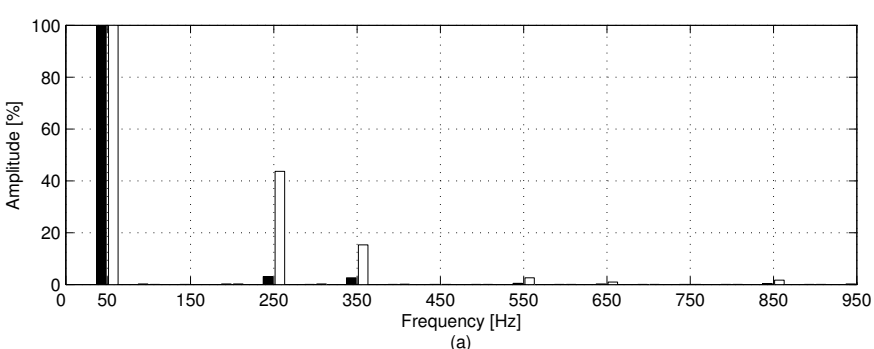

(a)
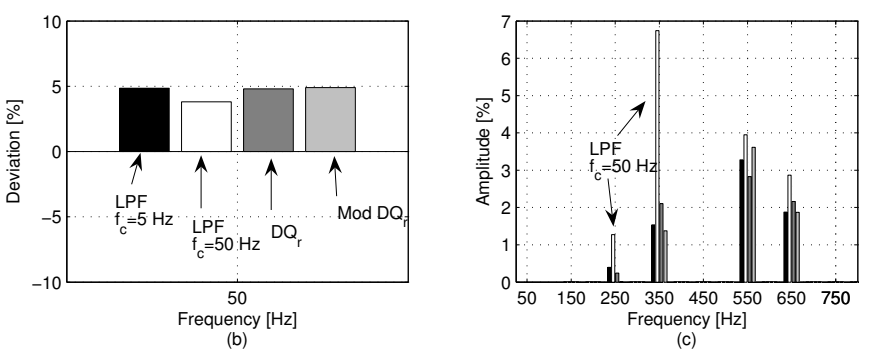

Fig. 12. Compensation results in stationary state. a) Grid voltage and load current $\left(V_{\text {base }}=20 V_{r m s}, I_{\text {base }}=2.21 \mathrm{~A}\right.$ ) in phase $\mathrm{A}$, b) deviation from the fundamental component of the source current and c) amplitude of the harmonic components of the source current

as constant-length circular buffers and $\hat{x}_{d q}$ are obtained by means of two discrete integrators. The implementation of the modif ed $D Q_{r}-D Q^{-1}$ method requires the measurement of the grid frequency $f_{P L L}$ in order to establish the window length $N^{\prime}$ of $\Delta$ operators. As a consequence, two circular buffers with variable length have been employed. The maximum and minimum length is bounded by the grid frequency limits. The obtained values are transformed to a rotating frame where small frequency drifts are compensated by applying $\Theta$.

\section{B. $N_{r}$ equals $N$}

Fig. 12 shows the experimental results obtained during the compensation process of the non-linear load by means of the analyzed SRF controllers. As can be seen in fg. 12.b there is a deviation from the load current consumption at the grid frequency. This is due to the fact that a portion of the load active power is supplied at the $5^{\text {th }}$ and $7^{\text {th }}$ harmonics. Once the SAPF is being operated properly, these harmonic currents must disappear from the source current spectrum. As a consequence, and in order to avoid the active power mismatch, the SAPF must increase the amplitude of the fundamental component 

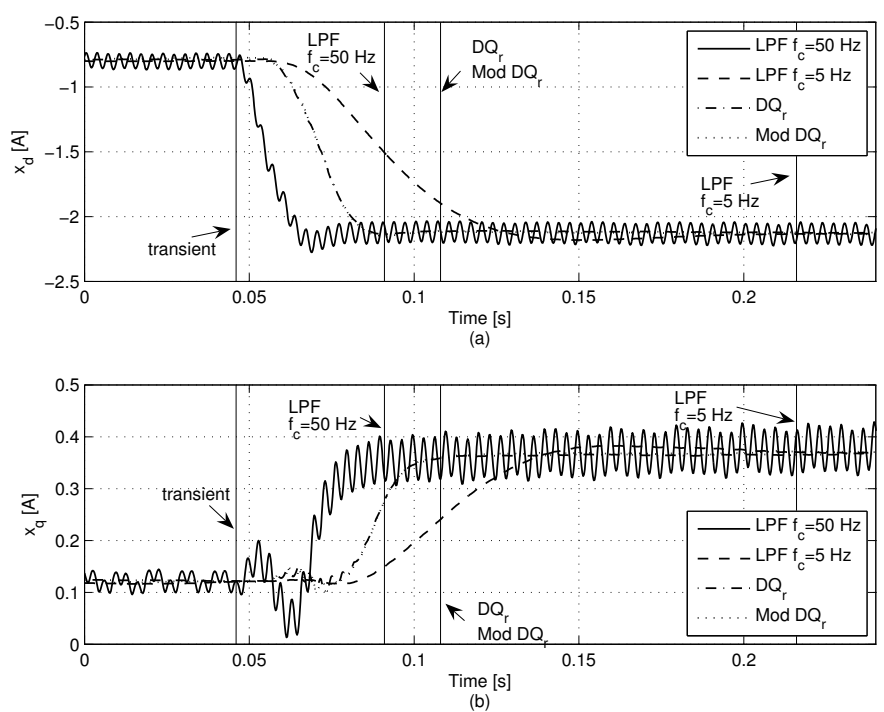

Fig. 13. Response to a load transient. a) $d$ and b) $q$ components of each SRF based controller

of the source current. The lowest deviation is measured for the $f_{c}=50 \mathrm{~Hz}$ LPF-based controller $(4.1 \%)$ and, as will be shown in fg. 12.c, this is due to an erroneous harmonic compensation which requires a lower active power to be supplied through the SAPF. It must be considered that the obtained experimental results differ from the simulation ones (f g. 5.b) due to the fact that in the f rst case only the electrical grid supplies power to the PCC but, in the second case and considering the SAPF as an ideal controllable current source, the power balance at the PCC can be also changed by the SAPF.

The measured source current is shown in fg. 12.c. As can be seen, all the analyzed methods compensate the $5^{\text {th }}$ and $7^{\text {th }}$ harmonics of the load current. The method involving the $f_{c}=50 \mathrm{~Hz}$ LPF exhibits the lowest performance, with 1.28 $\%$ and $6.74 \%$ for these harmonics respectively.

A load transient has been applied by means of switch $s w$ at $t=0.046 \mathrm{~s}$. The evolution of $d q$ components for the SRF-implementations under test is shown in $\mathrm{fg}$. 13.a and 13.b. As can be seen, the fastest response time corresponds to the LPF-based SRF method with $f_{c}=50 \mathrm{~Hz}(45 \mathrm{~ms})$ while the slowest implementation is the LPF-based one with $f_{c}=5 \mathrm{~Hz}(170 \mathrm{~ms})$. Both recursive implementations have equivalent response times $(61 \mathrm{~ms})$. The response time of the recursive implementations depends on the PCC voltage and current signal characteristics while the response times of LPFbased methods depend also on the low pass fltering stage characteristics.

The instantaneous values of the PCC currents in case $N_{r}=$ $N$ (the grid frequency is $50 \mathrm{~Hz}$ ) during the compensation process of the non-linear load current are shown in $\mathrm{fg} .14$. The initial load current has a THD equal to $70.3 \%$. Once the SAPF has reached the stationary state and, applying the LPF based methods with $f_{c}=50 \mathrm{~Hz}$ and $f_{c}=5 \mathrm{~Hz}$, the source current THD is reduced to $8.4 \%$ and $4.3 \%$ respectively. The difference between the reached THDs is due to characteristics
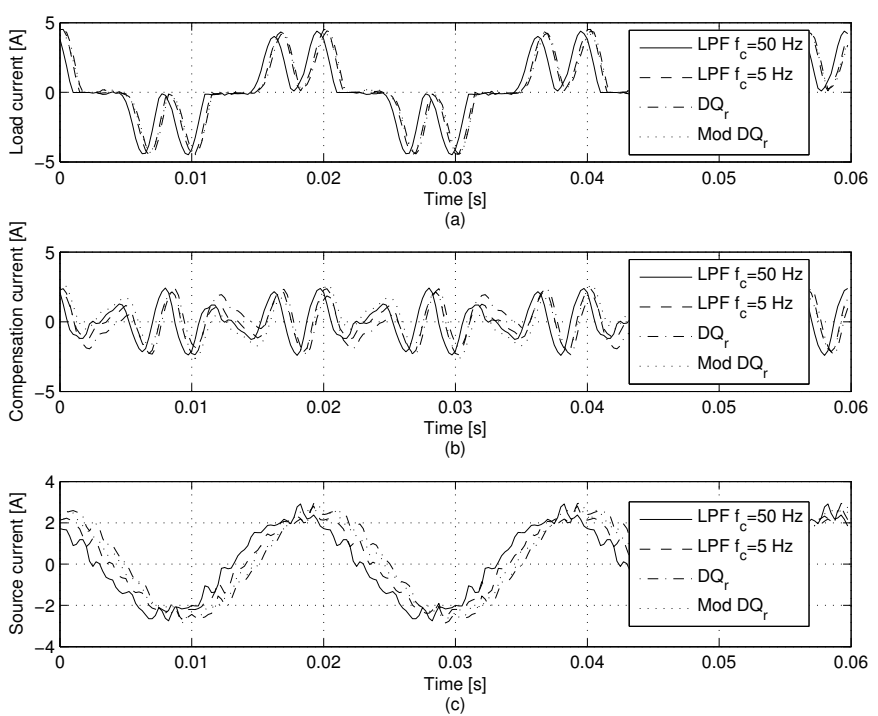

Fig. 14. Measured currents at the PCC at $50 \mathrm{~Hz}$ in phase $\mathrm{A}$. a) load current b) compensation current and c) source current.
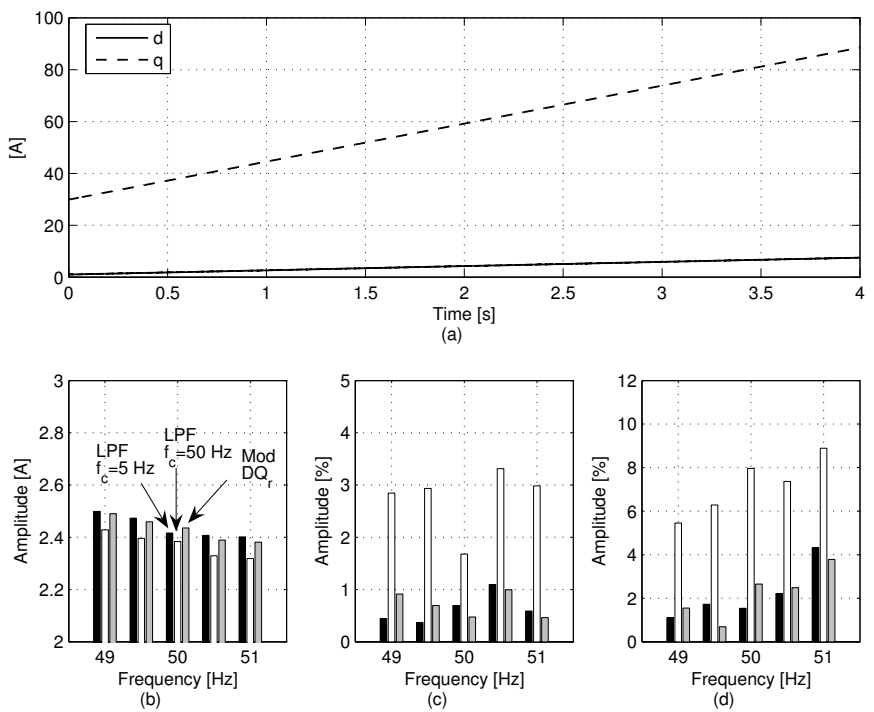

Fig. 15. Operation with $N_{r} \neq N$. a) $d q$ components of the $D Q_{r}$ controller with $f_{P L L}=49 \mathrm{~Hz}, \mathrm{~b}$ ) fundamental component of the source current in phase $A$, c) $5^{t h}$ harmonic of the source current in phase $A$ and d) $7^{\text {th }}$ harmonic of the source current in phase $A$. The test frequencies are 49, 49.5, $50,50.5$ and $51 \mathrm{~Hz}$

of the applied LPF in each case. The $D Q_{r}$ based controller and its modif ed version also reach low THDs, $4.2 \%$ and 4.3 $\%$ respectively.

\section{Different $N_{r}$ and $N$}

The SAPF controllers have been tested by applying grid voltage frequencies between the range $[49,51] \mathrm{Hz}$ with 0.5 $\mathrm{Hz}$ variations. Moreover, the resonance frequency of the current controllers have been changed during the tests in order to avoid their effect on the comparison. Fig. 15.a shows the $d q$ components evaluated by the $D Q_{r}$ method. As can be seen, due to $N_{r} \neq N$, the recursive implementation fails during the evaluation of the actual $d q$ components of the load current. 

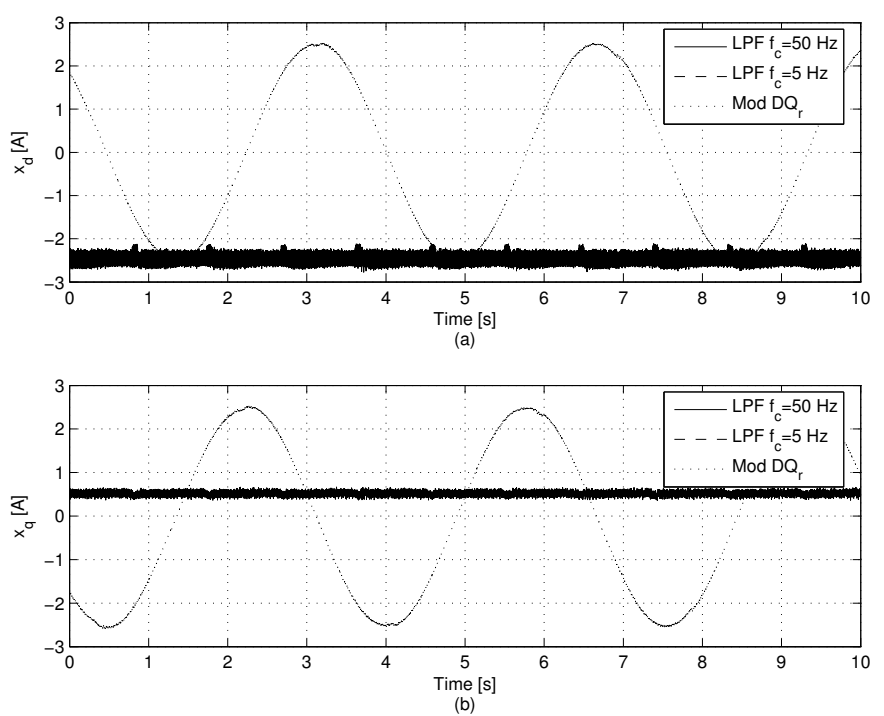

Fig. 16. Operation with $N_{r} \neq N$ at $f_{P L L}=51 \mathrm{~Hz}$. a) $d$ and b) $q$ components of the LPF and the modif ed $D Q_{r}$ based methods

As a consequence, after the SAPF initialization, the overcurrent protection of the laboratory setup trips out and the SAPF is stopped. Hence, the operation of the SAPF prototype at frequencies in range $[49,51] H z$ has been tested with LPF-based controllers and the proposed modif ed recursive implementation.

Fig. 15.b shows the measured fundamental component of the source current with compensation at the test frequencies $(49,49.5,50,50.5$ and $51 \mathrm{~Hz})$. As can be seen, increasing the test frequency reduces the load current consumption and, as a consequence, the fundamental component of the source current. This effect is due to the fact that higher grid frequencies reduce the discharge transient of $C$ while lower grid frequencies make this transient longer, which requires higher peak currents recharge this fltering capacitor ${ }^{P}$. The current consumption of the LPF-based controller with $f_{c}=50 \mathrm{~Hz}$ is the lowest one in all tests, which is due to errors in harmonic compensation.

The relative amplitude of the measured $5^{\text {th }}$ and $7^{\text {th }}$ harmonics of the source current after compensation are shown in fg. 15.c and 15.d respectively. As can be seen, the LPFbased implementation with the lowest cut-off frequency and the proposed modif ed recursive implementation obtain similar results while the $f_{c}=50 \mathrm{~Hz}$ LPF-based controller can not compensate the load current harmonics properly.

The $d q$ components evaluated by means of the tested SAPF controllers are shown in fg. 16. The programable power generator fed the non-linear load at $51 \mathrm{~Hz}$ in order to obtain this f gure. The LPF based methods obtain equivalent results as in the case of $N_{r}=N$. Small notches in $d q$ components are due to the operation of the anti-windup protection associated to the dc-bus voltage controller (fg. 10). The modif ed $D Q_{r}$ method generates a proper reference current for compensation purposes due to a second transformation to a rotating frame. From $\mathrm{fg}$. 16, the period of the measured $d q$ components is $3.55 \mathrm{~s}$, which corresponds to $\frac{\omega_{\epsilon}}{2 \pi}=0.28 \mathrm{~Hz}$, the frequency of
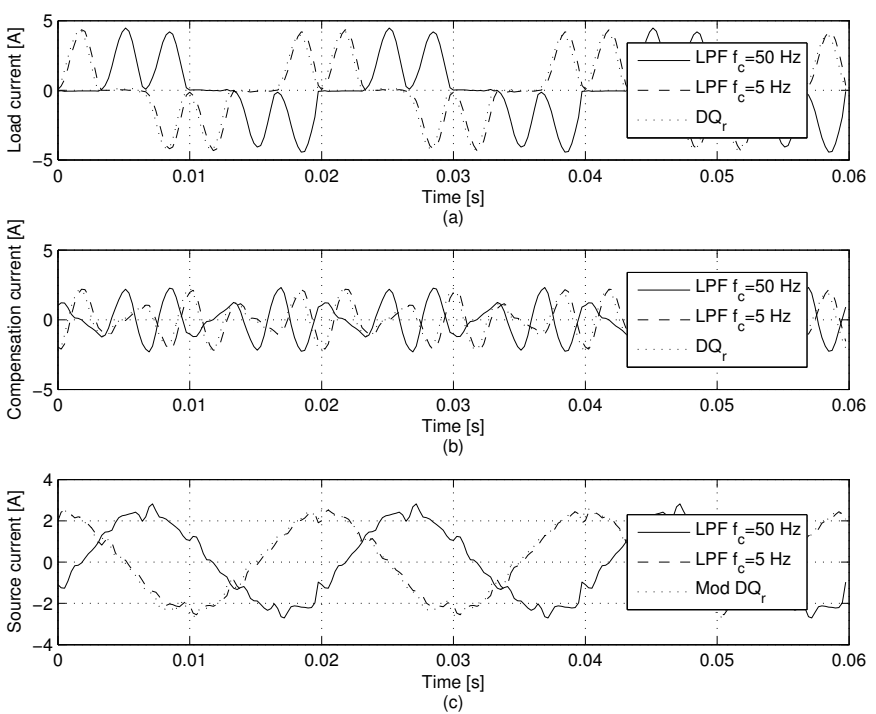

Fig. 17. Measured currents at the PCC at $51 \mathrm{~Hz}$ in phase $\mathrm{A}$. a) load current b) compensation current and c) source current

the second rotating frame. The controller adjusted the length of $\Delta$ operators from 80 to 78 samples. In case of the $D Q_{r}$ method, the overcurrent protection of the laboratory setup was tripped out while charging the dc-bus capacitor and, hence, the SAPF controller stopped the laboratory prototype.

The measured currents at the PCC, when the frequency of the programmable power source is $51 \mathrm{~Hz}$ and the stationary state is reached, are shown in fg. 17. As it was previously discussed, the results associated to the $D Q_{r}$ based controller are not depicted. The waveform of the source currents are quite similar in all the tested methods but the $f_{c}=50 \mathrm{~Hz}$ LPF based controller exhibits a higher ripple. The measured THDs reveal this effect. The initial load current THD is $72.1 \%$ and, applying the laboratory prototype of SAPF, it is reduced to $10.1 \%, 5.7 \%$ and $5.3 \%$ by means of the LPF and modif ed $D Q_{r}$ based controllers. As in previous cases, the best THDs are reached by employing a LPF stage with a low cutoff frequency and, equivalent results can be obtained by applying the proposed method. It must be considered that, in case of transients at the PCC and as it was shown in fg. 13, a low cutoff frequency results on a slower response time.

\section{Conclusions}

This paper proposes a recursive implementation of the Park Transformation which allows the improvement of SRF based controllers in shunt active power flters. Two recursive implementations, non-tolerant and tolerant to grid frequency variations, have been proposed and compared to LPF based implementations. A mathematical analysis, simulation tests and experimental results obtained on a laboratory prototype of SAPF are given. The obtained results demonstrate that the performance of LPF-based implementations depend on the PCC conditions and the fltering stage characteristics: controllers with low cut-off frequencies can be designed to obtain a good stationary state behavior but their response times to transients are high while controllers with high cut-off 
frequencies have fast response times and low performance in stationary state. The proposed recursive implementation can be applied without considering the PCC conditions and avoids the design stage associated with LPF-based methods. Moreover, the obtained compensation results in stationary state and the measured response times to transients make the proposed method suitable for the development of improved SAPF controllers.

\section{ACKNOWLEDGMENT}

This work was partially supported by the Spanish Ministry of Science and Innovation under grant ENE2007-63979/ALT.

\section{APPENDIX \\ FREQUENCY DOMAIN ANALYSIS OF $D Q_{r}-D Q^{-1}$ CONTROLLERS}

The proposed $D Q_{r}-D Q^{-1}$ based controller can be analyzed in the frequency domain by applying Euler's formula to (11):

$$
\begin{aligned}
\left(\begin{array}{l}
\hat{x}_{d} \\
\hat{x}_{q}
\end{array}\right)_{k}= & \frac{1}{2 N_{r}}\left(\begin{array}{cc}
a^{k}+a^{-k} & -j\left(a^{k}-a^{-k}\right) \\
j\left(a^{k}-a^{-k}\right) & a^{k}+a^{-k}
\end{array}\right) . \\
& \left(\begin{array}{c}
\Delta\left(x_{\alpha}\right) \\
\Delta\left(x_{\beta}\right)
\end{array}\right)_{k}+\left(\begin{array}{l}
\hat{x}_{d} \\
\hat{x}_{q}
\end{array}\right)_{k-1}
\end{aligned}
$$

where $a=e^{j \omega}=e^{j \frac{2 \pi}{N}}$. Considering the property

$$
\mathcal{Z}\left\{c^{k} f(k)\right\}=F\left(c^{-1} z\right),
$$

it can be transformed to

$$
\begin{aligned}
\hat{x}_{d}(z)= & \frac{\left(z^{N_{r}}-a^{N_{r}}\right)\left[x_{\alpha}\left(a^{-1} z\right)-j x_{\beta}\left(a^{-1} z\right)\right]}{2 N_{r}\left(z^{N_{r}}-z^{N_{r}-1}\right)} \\
& +\frac{\left(z^{N_{r}}-a^{-N_{r}}\right)\left[x_{\alpha}(a z)+j x_{\beta}(a z)\right]}{2 N_{r}\left(z^{N_{r}}-z^{N_{r}-1}\right)} \\
\hat{x}_{q}(z)= & \frac{\left(z^{N_{r}}-a^{N_{r}}\right)\left[x_{\beta}\left(a^{-1} z\right)+j x_{\alpha}\left(a^{-1} z\right)\right]}{2 N_{r}\left(z^{N_{r}}-z^{N_{r}-1}\right)} \\
& +\frac{\left(z^{N_{r}}-a^{-N_{r}}\right)\left[x_{\beta}(a z)-j x_{\alpha}(a z)\right]}{2 N_{r}\left(z^{N_{r}}-z^{N_{r}-1}\right)}
\end{aligned}
$$

The inverse DQ Transform in (4), employing Euler's Formula, can be represented as:

$$
\left(\begin{array}{c}
\hat{x}_{\alpha} \\
\hat{x}_{\beta}
\end{array}\right)_{k}=\frac{1}{2}\left(\begin{array}{cc}
a^{k}+a^{-k} & j\left(a^{k}-a^{-k}\right) \\
-j\left(a^{k}-a^{-k}\right) & a^{k}+a^{-k}
\end{array}\right)\left(\begin{array}{c}
\hat{x}_{d} \\
\hat{x}_{q}
\end{array}\right)_{k}
$$

and applying (28), it can be transformed to:

$$
\hat{x}_{\alpha}(z)=\frac{1}{2}\left[\hat{x}_{d}\left(a^{-1} z\right)+\hat{x}_{d}(a z)+j \hat{x}_{q}\left(a^{-1} z\right)-j \hat{x}_{q}(a z)\right]
$$

$$
\hat{x}_{\beta}(z)=\frac{1}{2}\left[\hat{x}_{q}\left(a^{-1} z\right)+\hat{x}_{q}(a z)-j \hat{x}_{d}\left(a^{-1} z\right)+j \hat{x}_{d}(a z)\right]
$$

Overall transfer functions for the proposed method can be obtained applying (29) and (30) to (32) and (33):

$$
\begin{aligned}
& \hat{x}_{\alpha}(z)=\frac{\left(z^{N_{r}}-1\right)\left[(z-\cos \omega) x_{\alpha}(z)-\sin \omega x_{\beta}(z)\right]}{N_{r}\left(z^{N_{r}+1}-2 \cos \omega z^{N_{r}}+z^{N_{r}-1}\right)} \\
& \hat{x}_{\beta}(z)=\frac{\left(z^{N_{r}}-1\right)\left[(z-\cos \omega) x_{\beta}(z)+\sin \omega x_{\alpha}(z)\right]}{N_{r}\left(z^{N_{r}+1}-2 \cos \omega z^{N_{r}}+z^{N_{r}-1}\right)}
\end{aligned}
$$

\section{REFERENCES}

[1] H. Akagi, "Trends in active power line conditioners," IEEE Transactions on Power Electronics, vol. 13, no. 2, March 1994. pp. 263-268.

[2] T. C. Green and J. H. Marks, "Control techniques for active power flters," IEE Proc. Electr. Power Appl., vol. 152, no. 2, March 2005. pp. 369-381.

[3] M. Sedighy, S. B. dewan and F. P. Dawson, "A robust digital current control method for active power flters," IEEE Transactions on Industry Applications, vol. 35, no. 4, July/August 2000. pp. 979-986.

[4] L. Asiminoaei, F. Blaabjerg and S. Hansen, "Evaluation of harmonic detection methods for active power flter applications," Proc. of the IEEE $20^{\text {th }}$ Annual Aplied Power Electronics Conference and Exposition, 6-10 March 2005, pp. 635-641.

[5] S.-J. Lee, H. Kim, S.-K. Sul and F. Blaabjerg, "A novel control algorithm for static series compensators by use of PQR instantaneous power theory," IEEE Transactions on Power Electronics, vol. 19, no. 3, May 2004. pp. 814-827.

[6] P. Salmerón and R. S. Herrera, "Distorted and unbalanced systems compensation within instantaneous reactive power framework," IEEE Transactions on Power Delivery, vol. 21, no. 3, July 2006. pp. 1655-1662.

[7] R. S. Herrera and P. Salmerón, "Instantaneous reactive power theory: A comparative evaluation of different formulations," IEEE Transactions on Power Delivery, vol. 22, no. 1, January 2007. pp. 595-604.

[8] O. F. Kashani and M. Braun, "Stability analysis of a compensated load on a grid to obtain unity power factor," in Proc. of the 2005 European Conference on Power Electronics and Applications, September 2005. 8 pp.

[9] V. M. Moreno and A. Pigazo, "Modif ed FBD method in active power flters to minimize the line current harmonics," IEEE Transactions on Power Delivery, vol. 22, no. 1, January 2007. pp. 735-736.

[10] J. M. M. Ortega, M. P. Esteve, M. B. Payan, A. G. Exposito and L. G. Franquelo, "Reference current computation methods for active power f lters: accuracy assessment in the frequency domain," IEEE Transactions on Power Electronics, vol. 20, no. 2, March 2005. pp. 446-456.

[11] I. Etxeberria-Otadui, A. López de Heredia, H. Gaztaaga, S. Bacha and M. R. Revero, "A single synchronous frame hybrid multifrequency controller for power active f lters," IEEE Transactions on Industrial Electronics, vol. 53, no. 5, October 2006. pp. 1640-1648.

[12] M. I. Milanés Montero, E. Romero Cadaval and F. Barrero González, "Comparison of control strategies for shunt active power flters in threephase four-wire systems," IEEE Transactions on Power Electronics, vol. 22, no. 1, January 2007. pp. 229-236.

[13] M. El-Habrouk and M. K. Darwish, "Design and implementation of a modif ed Fourier analysis harmonic current computation technique for power active f lters using DSPs," IEE Proc. Electr. Power Appl., vol. 148, no. 1, January 2001. pp. 21-28.

[14] S. Mariethoz and A. C. Rufer, "Open loop and closed loop spectral frequency active fltering," IEEE Transactions on Power Electronics, vol. 17 , no. 4, July 2002. pp. 564-573.

[15] J. Barros and E. Pérez, "An adaptive method for determining the reference compensating current in single-phase shunt active power flters," IEEE Transactions on Power Delivery, vol. 18, no. 4, October 2003. pp. 1578-1580.

[16] V. M. Moreno, A. Pigazo and R. I. Diego, "Reference current estimation under distorted line voltage for control of shunt active power f lters," IEEE Transactions on Power Electronics, vol. 19, no. 4, July 2004. pp. 988-994.

[17] D. N. Zmood, D. G. Holmes and G. H. Bode, "Frequency-domain analysis of three-phase linear current regulators," IEEE Transactions on Industry Applications, vol. 37, no. 2, March/April 2001. pp. 601-610.

[18] M. J. Newman, D. N. Zmood and D. G. Holmes, "Stationary frame harmonic reference generation for active flter systems," IEEE Transactions on Industry Applications, vol. 38, no. 6, November/December 2002. pp. 1591-1599. 
[19] P. Mattavelli, "A closed-loop selective harmonic compensation for active flters," IEEE Transactions on Industry Applications, vol. 37, no. 1, January/February 2001. pp. 81-89.

[20] J. Allmeling, "A control structure for fast harmonics compensation in active flters," IEEE Transactions on Power Electronics, vol. 19, no. 2, March 2004. pp. 508-514.

[21] J.-C. Wu and H.-L. Jou, "Simplif ed control method for the single-phase active power flter," IEE Proc. Electr. Power Appl., vol. 143, no. 3, May 1996. pp. 219-224.

[22] IEEE Std. 519-1992, IEEE Recommended practices and requirements for harmonic control in electrical power systems, April 12, 1993.

[23] F. Blaabjerg, R. Teodorescu, M. Liserre and A. V. Timbus, "Overview of control and grid synchronization for distributed power generation systems," IEEE Transactions on Industrial Electronics, vol. 53, no. 5, October 2006. pp. 1398-1409.

[24] L. G. Barbosa Rolim, D. Rodrigues da Costa, Jr. and M. Aredes, "Analysis and software implementation of a robust synchronizing PLL circuit based on the pq theory," IEEE Transactions on Industrial Electronics, vol. 53, no. 6, December 2006. pp. 1919-1926.

[25] X. Yuan, W. Merk, H. Stemmler and J. Allmeling, "Stationary-frame generalized integrators for current control of active power flters with zero steady-state error for current harmonics of concern under unbalanced and distorted operating conditions," IEEE Transactions on Industry Applications, vol. 38, no. 2, 2002. pp. 523-532.

[26] R. I. Bojoi, G. Griva, V. Bostan, M. Guerriero, F. Farina and F. Profumo, "Current control strategy for power conditioners using sinusoidal signal integrators in synchronous reference frame," IEEE Transactions on Power Electronics, vol. 20, no. 6, November 2005. pp. 1402-1412.

[27] L. Asiminoaei, C. Lascu, F. Blaabjerg and I. Boldea, "New current control structure for shunt active power flters," Proc. of the IEEE $41^{\text {st }}$ IAS Annual Meeting, October 2006. pp. 183-190.

[28] P. Lezana, C. A. Silva, J. Rodríguez and M. A. Pérez, "Zero-steadystate-error input-current controller for regenerative multilevel converters based on single-phase cells," IEEE Transactions on Industrial Electronics, vol. 54, no. 2, April 2007. pp. 733-740.

[29] D. Sera, T. Kerekes, M. Lungeanu, P. Nakhost, R. Teodorescu, G. K. Andersen and M. Liserre, "Low-cost digital implementation of proportionalresonant current controllers for PV inverter applications using delta operator," Proc. of the $32^{\text {nd }}$ Annual Conference of the IEEE Industrial Electronics Society, November 2005. 6 pp.

[30] D. G. Holmes and T. A. Lipo, Pulse width modulation for power converters. Principles and practice,. IEEE Press, 2003.

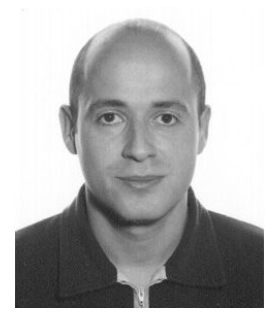

Alberto Pigazo (M'05) received the M.Sc. and the Ph.D. degrees in Physics (Electronics) from the University of Cantabria, Spain, in 1997 and 2004 respectively. Since October 2000 , he has been teaching courses of electronics, power electronics and digital signal processing at the Dept. of Electronics and Computers of the same university where he is currently an Assistant Professor. Dr. Pigazo has been a visiting researcher and professor at the Polytechnic of Bari, Italy, and he is member of the IES Technical Committee on Renewable Energy Systems (TCRES). He is also an Associate Editor of IEEE Industrial Electronics Magazine (IEM) and contributes as author and reviewer for IEEE journals and conferences.

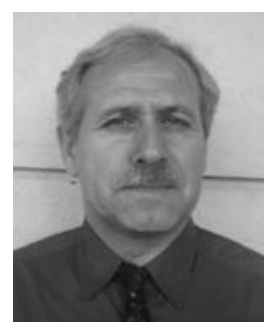

Víctor M. Moreno (M'01) received the M.Sc. and the Ph.D. degrees in Physics (Electronics) from the University of Cantabria, Spain, in 1980 and 1994 respectively. His Ph.D. thesis, entitled "Distributed Measurement and Analysis System for Power Quality in Electrical Grids Applying Kalman Filtering", received the Viesgo Award in 1994. Dr. Moreno is an Associate Professor at the Dept. of Electronics and Computers, University of Cantabria, Spain and teaches electronics, power electronics, and signal processing techniques at the School of Nautical Studies, University of Cantabria. He is member of the IEEE Power Electronics Society (PELS) since 2001 and contributes as an author and reviewer for IEEE journals and conferences.

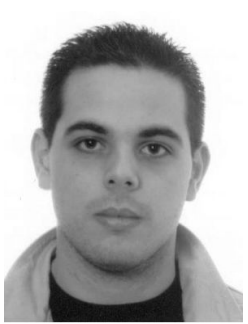

Emilio J. Estébanez received the M.Sc. degree in Telecommunications Engineering (Radiocommunications) from the University of Cantabria (Spain) in 2007. He is currently working as a researcher in the project ENE2007-63979/ALT "Islanding detection algorithms for low-voltage grid-connected inverters in photovoltaic distributed generation systems according to the EU standards (IDAPhoS)". 